\title{
地球物理方法勘探地下凟源工作 全面望習㿥聯以後的新方向
}

\author{
顧 功 叙
}

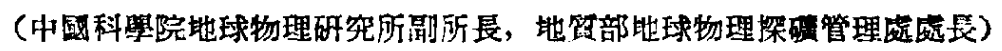

在中囦, 大規模使用地球物理方法來壽找與 勘探地下醌産資源, 開始於全國解放之後。這四 五年內的工作，是一段迁迴曲折的營試過程。今 天回想起来, 我們可以看到如果没有䔉聯的先進 綯驗作䉆指導, 就不知道將要再走多少年的路路。

當初，我阿在英美資本主義國家留過縣的人， 一般都承衿地球物理勘探力法是倠得進一步础究 的科學方法, 可是我荫認篇它目前還非常纤稚, 祀在探筧石油構造的問題上起過比較滿意的作 用, 有磁性的䧔伏鐵酸, 一般也可以有效地使用 磁法测量。但是地球物理方法在許多有用碳楥的 勘探上是否有效果, 大家都设有把握。常時, 大 家對蘇聯地球物理撕探工作的發展情况很不了

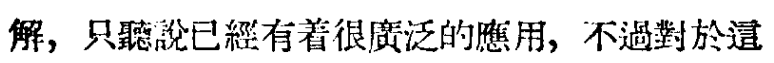

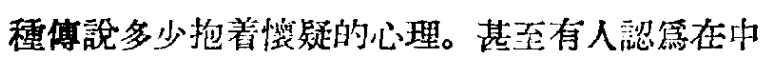
國援大進行地球物理的勘探工作, 目前澴沒有可 能。

那封候推酎摭大和發展地球物理探磁工作的 指隼思想是很模糊的, 主要包括造等兩點: (1) 中國的地啠人員的人数在幾年之內計劃要摭大成

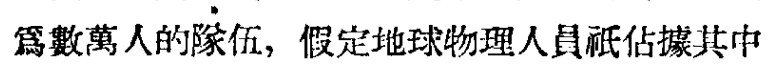
的十分之一，就需要數干人。每十倜地質工作者 有一個地球物理人員隶配合工作，估訂是不致於 人手過剩的。(2) 地球物理微探的技術不足是事 琠, 但是可以從大量工作中訨靠多教人的智慧來 提高技術水平。然而也有人懷疑並反對這種看法。

地球物理勘探工作在我國的發展, 並没有因 第某些人的溹疑而受到决定性的影響，近䋐年來， 終於以空前巨大的規模在全國範圍队展開了工 作。主要的收權有: 1. 在勘探石油地算方面, 由於
燃料工業部石油管理總局的地球场理勘權的成 果, 指導了隐藏石油地質構造的墢現。2. 在找叠

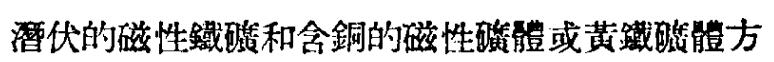
面, 地質部和重工業部的地球物理䒨探工作會經 發揮了一定的作用, 解决了一些問題。3.各部門 在工作中也都迅速地培䓹了一六批地球物理勘探 的技術人員, 初步添置了一些儀器戥诺, 使地球 物理勘探力量在中國的地質工作除伍中開始成長 和䖪大起來。但是, 今天攏在中國地球物理勘探 事業面前的最噘重的問题, 㙷然是如何使地球物 理方法更廣泛地用來找到更多種類的與不同座狀 的有用眏産, 否则就不能㴖足正在飛速開展中的 地質勘探工作的要求。同時, 如果不能在造一閵 䣄問題上找到出路, 地球物理勘探事業本身的發 展也就必將遭致最䈯重的限制。

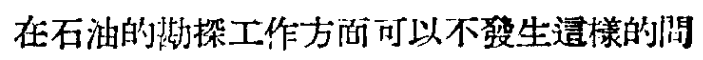
題, 因篇地球物理方法對研究石浽構造來說, 巳

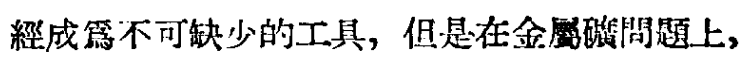
它椚的應用前途却酌臨着考騟。

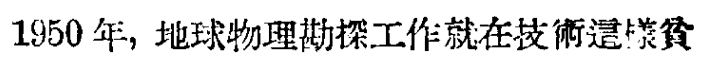

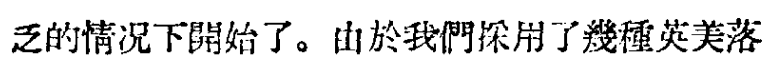

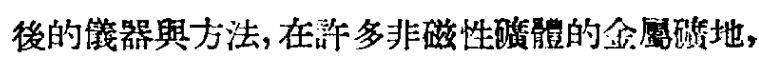

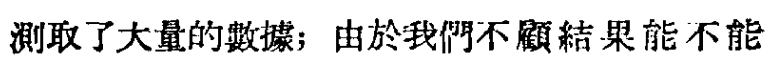

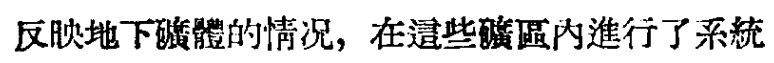
的“掃而皘”工。作，因此，獲得的數摭大部不說明 任何問題, 絬果當然很難使人滿意。在盍同時, 許多勘探榢提出要冰解决的問題, 日盆槙雜興困 難，因此工作任務與地球物理技術之間的矛盾日 益尖錴化起來，地球物理工作在整倜地啠撕探工 作中的技術上的威信也就不能迅速地建立。每头 
裳地球物理人員向勘棎除請求任務的時候, 他們 的答缺是: 希望解决的問題很多, 只看地球物理 方法能不能起作用。但是這種希望解决的問題,

一般都是很嚾着手的。例如他們常常要求測定直

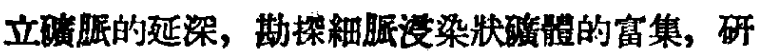
究距離地表很深（500 公尺以下）部分硯體存在

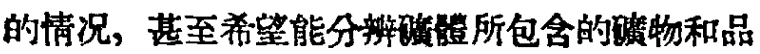
位，尋找地下古坑道的分侑等。

目目地生産大量不說明問題的數搭的工作經 過了批制, 在 1953 年下牛年提出了生產結合貝驗 的方針，要求各地酒的地球物理䒨探工作必須針

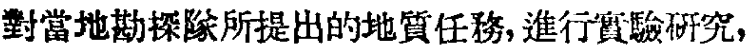
從而獲取有用的數摭隶解决地質問題。但是對如 何實驗，如何研究，還缺乏明確的意見; 對預期 能達到什㦄成果也很少估計，因而就得不到什縻 結果。

到 1954 年上牛年, 篇了紏正惯驗工作的乱拼

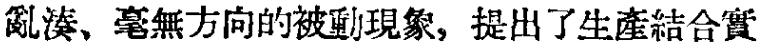
驗研究的工作，必須先有具體的設計，以明確工 作的目的與步琹。但是，當時只考甞到地球物理

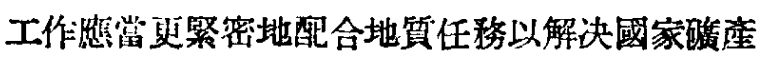
勘探工作中所存在着的一切疑蜼而迫切的問題， 所選擇的地質任䂫，絕大部分是地球物理方法很 難處理的地質問題。而且大部分地區的工作所提 出的設計，由於詐多筧際的技術因素與估計相差 太遠，很難学握，而大都落空，並使工作的性筫 形成無限度的望䮑研究。因此再一次陷於技術遠 遠配不上任務的苦䦓局酌。

漬裹應該提到，今年開始我們獲得了一些蘇 聯地球物理䓵探㻎籍, 學習了其中的一些原理、 方法與儀器構造, 按照蘇聯規格抄製了一些電法 勘探的儀器, 盡量探用蘇聯操作規程來進行野外 測定。但是大家對蘇聨地球物理㘩探技断的理解 只限於書本範園以內，僅僅包括方法和儀器，至 於在害際工作中如何運用各種方法独獲致地質效 果，體會極不深刻。因此1954年上牛年我們只

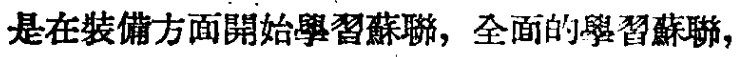
技鿉上得到更重大的革新還在後面。

正在地球物理方法㓻探金屬础的工作方向不 明、茂術上最困難的時候，從蘇聯來了幾位地球 物理曹家，他們經過一段時期了解情况，指出我 們過去工作上的主要缺點是在於選擇勘探任務不
恰當, 因而使地球物理工作澴没有员正開始解决 地質勘探問題。他們建議中國的地球物理勘探事 業要走蘇聯的道路, 但是要避免在蘇聯已走過的 型路, 從防可以縮短發展的過程。他倨也指仙, 目前中國地球物理探酸的情况，在蘇聯革命成功

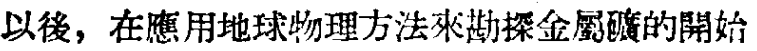
階段也曾鱾遇到過。地質㘩探人員也提出過䚺多 不是地球物理方法能够解决的地質磷休問題而要 求解决, 因而也就使地球物理工作完全不能適應 於需要。蘇聯地球物理工作者經過了多年的摸奖， 把一些嚄方法的作用重新加以試驗和評價，倧止:

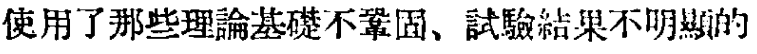
方法, 同洔在勘探任萔方面停止接受不坷能用地 球物理方法解决的問題，因而使大部工作星軧向

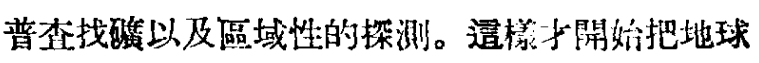
物理脚探工作引入了正確的道路, 塹固了它在整 倜地犋勘探事業中的地位。

中國的地球物理斯探工作必须寥考䰻聯的經

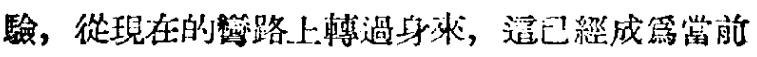
無可逊延的革新方向。相據蘇聯專家的建垶義和我

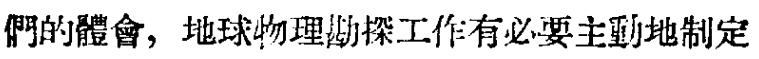
自己獨立的工作計劃和五年、十年……的遠景計 剖, 計劃的內容應該是:

1.大量的工作是遠遠跑在地質工作前的行不 瞈離地筫工作和國家撕探任䧄的區域性地球吻埋

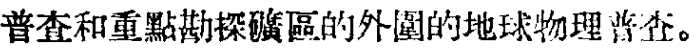

2. 一部分工作是斯探榢所提出的们又等地球 物理學肯定能解决的地咓碳床阔題的勘探工作。

3. 小部分是試驗和鑽呼新的方法、儀器和意 見的筫䭼研究工作。

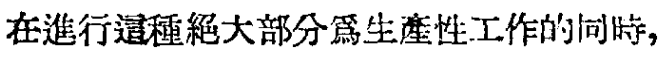

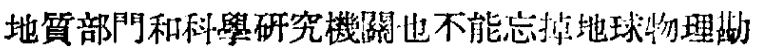
探的科基研工作, 塄一研究工作基礎门建泣, 今天已到了不允蔀再㜊延的地步。

關於把地球物理工作的主要力量轉向普企造 一點, 由於我們在不久以前, 頭腦中造允滿着完 全相反的思想, 就是地球物理不能跑離地質副企 地區的範園，因此在開始時不易體會。但是當·我 陫不再局限於那些地球炀理方法目前所不能解决 的困難問題, 而稍稍多着眼一些整㑬地質勸探工 作遠景方面的問題時, 我們就會很迅速地從思想

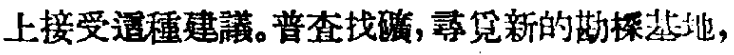


今天已經成霑地筫部門頭等迫切的任移，地球物 理工作如果能在遭裹發揮很好的作用, 同榡是圆 家所絕對必需的。

我們從葆聯專家的介結中了解到，由於幾十 年來, 地球物理勘探技術在蘇聯大規模發展, 已 經創造了幾種新的技術, 可以作営普查的有效工 具。運用造些技術可以配合地質普查工作，也可 以跑在地質普查的前面。在只有極初步的或只有 一些大致概念的地質資料的廣大區域上, 用這些 茂街可以進行系統的工作效率極高的地球物理測 量。在幾千平方公里至幾十萬平方公里的大面積 上, 地球物理數據的買常, 顯示出一些可能的地 下地質現象, 從们引導地質工作向這種重點地區 進一步们置工作。地球物理探取這樣方式來指示 新䀧地的發現, 顯然比較企圖在幾處已知碳區解 决一些勘探中的䧼題要有意涹得多。方其在完全 掩藍的平原地遌, 缺乏路頭或是路頭不明顯的其 它地區, 賞地質觀察不可能進行時, 地球物理墈

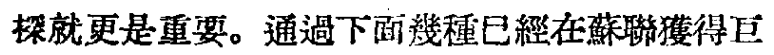
大成就的地球物理普查技政, 我們可以更深入地 來理解這一意義。

1. 航空磁測或地面磁測搜尋超基性岩體興磁 鐵砤。

超基性岩體和詐多金屬础如䤼、鉻、銅的閵 係是很密切的, 從找到超學性岩體來指示這種金

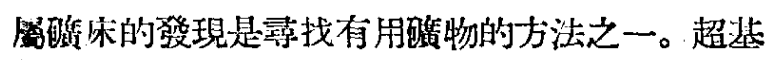
性岩石具有較强的磁性, 可以在磁力圖上表現出 來。航空磁測工作允許在很短的時間內完成廣大 面積的磁測，因而可以迅速地找出超基性岩體的 分佈範圍。我國土地這樣大，没有被弡現或是份 被掩潐的超基性岩體必然很多, 航空磁测是最需 要的。對未發現的磁鐵磪産地的搜尋, 航空磁测 的作用當然更不必提了。地面磁測也可以迋到问 滕的目的，不過速度太低。交通不便、人跡不能 到達的地區, 也不可能進行。

2. 等電位綫法與自然電流法搜尋較巨大的良

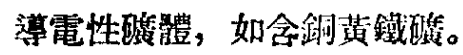

過去我們不能想像等電位綫法對金屬碳的探 測可以產生任何有意義的效果。紃過蘇聯專家的 介紹, 才知道通一方法在蘇聯已紃很成熟地被使 用來大規模普查鮗伏的良導電性碃軆, 得到了極 良好的結果，指導了金屬磄的地質勘探工作的前
進。

造裏應該提到，等電位絟法是經過了改進才 能這樣有成效的。在儀器構造和供雪電流虽度方 面都有了新的發展。不過主要繁是因篇等電位䋨

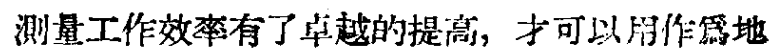
球物理普查的工具。

3. 重力法、電測深法、磁法、地震法亚查石 油煤的地質構造。

被冲積屡覆蓝着的廣大本原、盆地、沙漠等 的地下地質構造問題, 無例外地是地球物理工作 最理想的對像。從發現和研究地下地質構造, 往 往能找到石油和煤田。通方面的工作, 要把多種 地球物理方法相互配合起來使用，如重力、電測 深、磁法與地震法, 因此工作量是最巨大的。

在配合已知缩區地質勘棎工作方面，蘇聯地

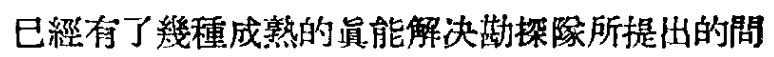
題的地球物理技術，大致是:

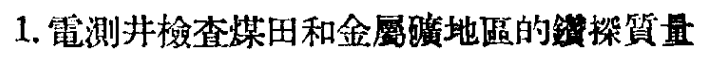
以及鑽孔柱狀地質悋面的正確程度。

2. 電测深法貓探煤田地區的具體構造和用電 測深法研究金屬磈區的一些相當的䦌題。

3.地面磁測和自然電流法勘探銅、䤼硫化物 睡體的存在。

4. 重力儀和扭科法在地形平緩地帶勘探埋藏 不深的鉻鐵碳體的存在、煤田的構造、磁性與非 磁性鐵砤的存在等等。

5. 地的磁测勘探磁鐵碳的存在。

6. 對比折射地震法和一般地震法勘探煤田和 石油的地質構造。

如果能在使用這橥方面的具體技衡之前, 先 作周密的設計, 就一定都能獲得預定的地質效果。

由於任務方向經歴了這一重大的轉變, 不久 以前我們還認爲是技術不成熟。大部分的工作量 是實驗研究性的地球物理䒨探工作, 一變而篇紹 大部分是生産性的了。無論在區域䇤查或在詳細 勘探中, 對地球物理工作都可以制定有效的工作 計劃，規定一定的任務，解决一定的問題。稘栐就， 可以把工作納入正常的軌道，打開今後更大發展， 的門徑。

同時, 由於這一轉變，顯然巳使中國現有的 比較漆弱的地球物理勂探力量（人力與配備）和 全國需要在最近五年或十年以內進行的障大地球 
物理勘探工作, 在數量上完全不相稱了。過去有 一段時期，地質部門的許多工作都感到“任務大， 力量小”，唯獨地球物理探础當時存在着所請“任 務小，力量大”的不正常現像。到今天看來; 這完 全是由於工作本身所走的方向不正確所引起的。 大量能發揮生産意義的地球物理任䅂没有接受, 而把力量祇紏纒於少數不易解决的勘探問題上, 就很自然地會造成不得發展的局面。如果考虑到 中國的廣大疆域, 以地球物理勘探工作新的拱展 尺度來作估計, 就可以看到現有的力量是極第不 哆的。甚至即使達到全部地質工作規模的十分之 一，也遝完全不能滿足任務的要求。因此，現在我 们必須再一次考虑更大規模的發展。當然我門不 能否認，在目前科技術的水平不高、許多配備 立副機械化還不可能、國家投資也有限度的情况

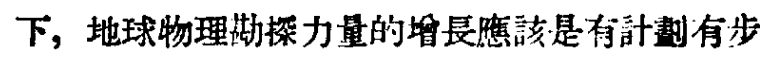
磷的。在破展過程中必然還會群到訐多困難，不 過方向已称朋確，具體困蜼是能够克服的。

通過了這一轉變，也使我們進一步涊識到地 球物理䒨探事業在蘇聯的發展與成就和蘇聯尘進 科舅的侵越性，認識到在全世界任何國家內都還 處於極幼稚地位的地球物理勘探事業, 已經在蘇

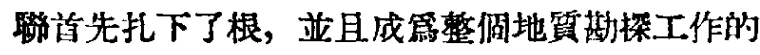
愈來愈不可缺少的一部分。當然，落聯專家也强 調指出，今天的地球物理勘探技術必須在卯緊科

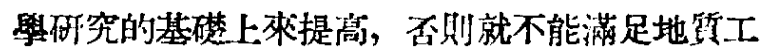
作對地球物理提出的日谷廣泛的要求。通種科缺 研究工作如何正確地配合桃進行，也是當前很值

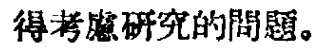

\section{〔上接 14 頁〕}

對磷分解細菌的分離和培養, 使它適用於我 國的自然佟件，還有很鞎䤠的工作在前面。

（五）生物作用和化與作用的結合: 在堆肥 中加入少量 (2.5\%) 硫酸銨, 㙷然地增進了磷灰 土及磷灰石的可給性。這點在穌聯和英、美都已 經有過試驗。硫酸锖經過确化作用，產生硝酸和 硫酸的離子，這项酸性唯子㙷然有助於磷砾粉的 分解。在用生物方法改進磷肥功效的時候, 罯應 該多方面地考虑到化潞作用。

（六）注意作物：各稞植物對领肥料的吸收 能力是迥然不同的。一般講柬, 緑肥牧草對於磷 酸粉的利用能力比較强（如油茨、落萄获、落子、 蓄麥、豬屎豆、木豆等)，而教類作物直接吸收磷 灰石的性能通常是低的。這樣，如果把磷罍粉施 用於綠肥牧草，通過線肥牧草再來提高数類作物 的産量, 應該更有效些。

（七）注意土壤: 如果就華䓟的酸性土壤(主
要是紅壤)、東北的黑土以及華北黃土性 (强石灰 性）土壤來此較，那末磷灰石在紅翌中的功效應 該是最强，黑土次之，而强石灰性土壤通常最 低。以後的施用地域也要隨不同土堆融有澡别。 因此磷灰石試驗與其普遍地進行, 不如有满點地 來做。

（八）注意施用方法：像磷灰石㯰樣不溶性 的肥料，它的施用一定要集中，而施用位置必須 和根部接近，因此每站 100 斤以下的用量（如果 類似蘇排的磷灰土生物處理力法我們浐没有侙驗 成功)，通常是過低的。而在任何情况之下，應融 以條施桃代替目下大部試驗所探用的普施。

最後, 我們建議：組織一部分農業、土壤感

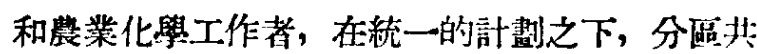
同進行磷灰石利用試驗，以求遭一個問題的徹底 解决。我阴寧可做得少些，但數做得好些。 